\title{
Rhinocerebral Mucormycosis: The Indian Scenario
}

\section{Dr Avani Jain, Dr Ravi Meher, Dr JC Passey, Dr Ramanuj Bansal}

Maulana Azad Medical College and Lok Nayak Hospital, New Delhi, India

\section{INTRODUCTION}

- Mucormycosis is a rare opportunistic fungal infection with a fulminant course and high mortality rate.

- Caused by filamentous fungi of the Mucoraceae family.

- Rhinocerebral mucormycosis primarily involves paranasal sinuses but often progresses to involve the orbit and intracranially.

- Occurs in immunocompromised hosts with uncontrolled diabetes, hematologic malignancies and solid organ transplants.

\section{MATERIALS AND METHODS}

- 52 patients treated for rhinocerebral mucormycosis over a 5-year period (2013-2018) were analysed.

- Diagnosis was confirmed by histopathology

- Data regarding the age, sex, predisposing factor, clinical features, treatment, and outcomes were recorded.

\begin{tabular}{l|l|l|}
\multicolumn{3}{c}{ RESULTS } \\
\cline { 2 - 3 } $\begin{array}{l}\text { - } 52 \text { patients } \\
\text { - Age: } 6 \text { months- } 65 \text { years }\end{array}$ & Rhinomaxillary & 8 patients \\
\cline { 2 - 3 } - Males: 28, Females: 24 & Rhino-orbital & 34 patients \\
\cline { 2 - 3 } & Rhinocerebral & 10 patients \\
\cline { 2 - 3 }
\end{tabular}

- Males: 28, Females: 24

\section{Predisposing factors}

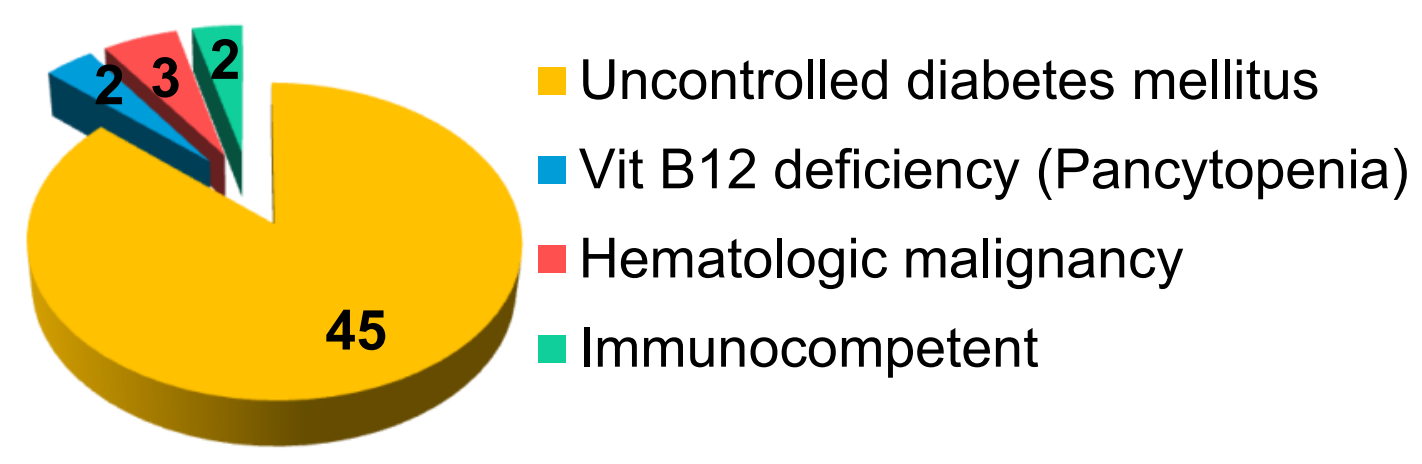

\section{Clinical Features}

Hemiparesis/hemiplegia $\square 4$

Altered sensorium 5

Facial paralysis $\quad 5$

Involvement of cheek skin $\quad 11$

Oroantral fistula 18

Nasal discharge/ sinusitis $\quad 27$

Nasal obstruction $\quad 35$

Fever 37

Reduced vision 41

Facial/ periorbital swelling $\quad 42$

Headache/ facial pain 52

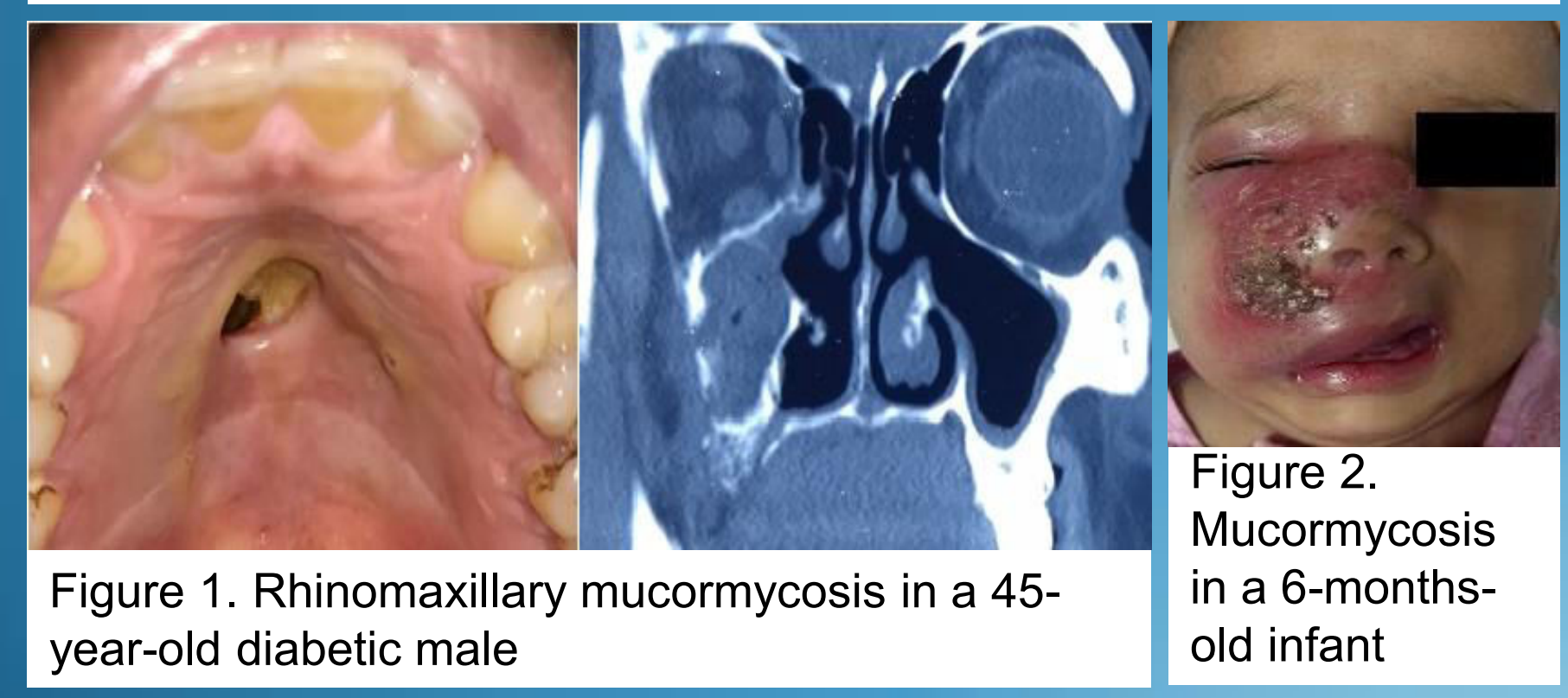

1. Ketenci İ, Ünlü Y, Kaya H, et al. (2011). Rhinocerebral mucormycosis: Experience in 14 patients. J Laryngol Otol 125(8): e3.

2. Jung SH, Kim SW, Park CS, Song CE, Cho JH, Lee JH, et al. rhinocerebral mucormycosis: consideration of prognostic factors and treatment modality. Auris Nasus Larynx. 2009;36: 274-9.

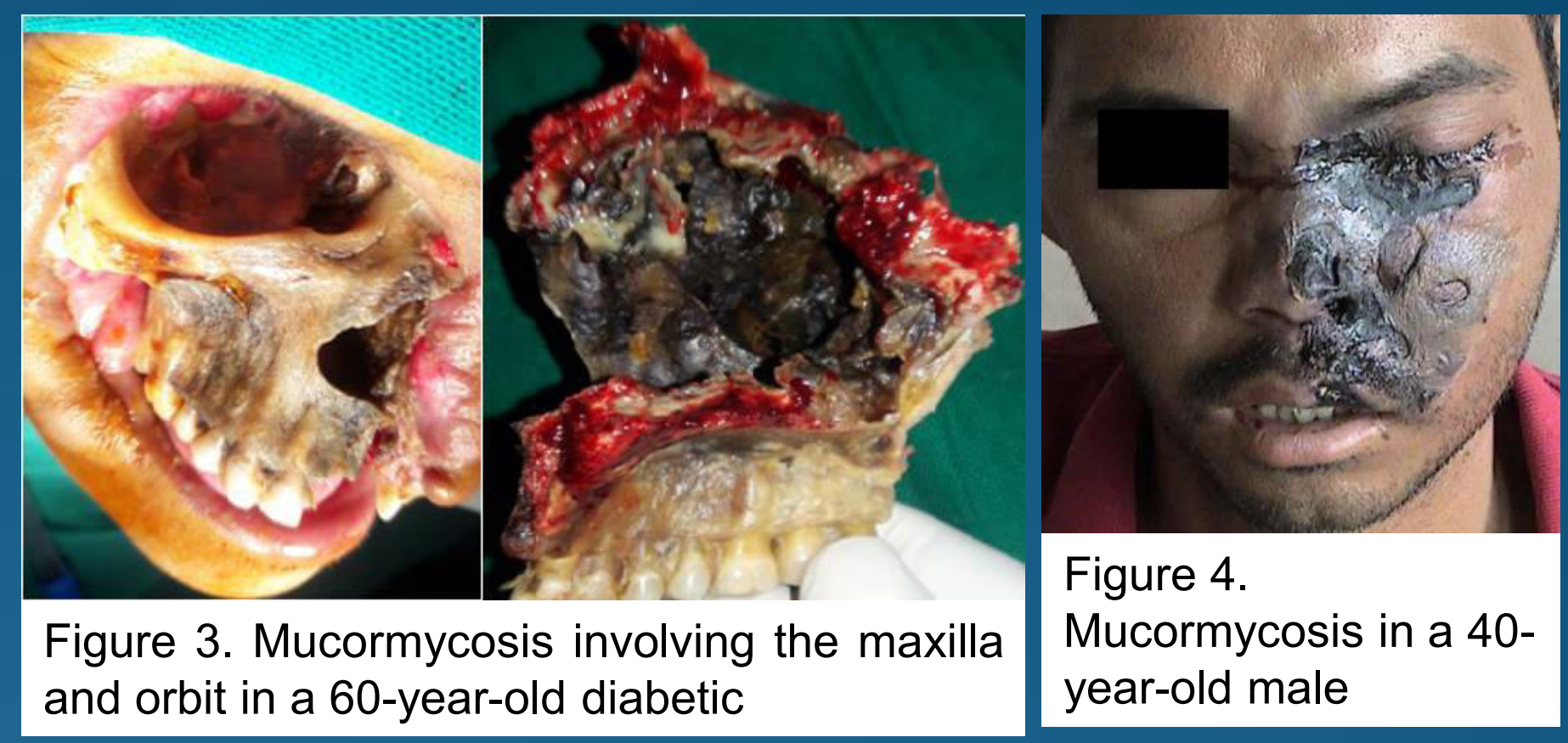

\section{Treatment:}

- All the patients underwent both surgical and medical management.

- Identification and treatment of predisposing cause

- Surgical debridement:

- Endoscopic debridement: 20 patients

- Partial/ infrastructure maxillectomy: 17 patients

- Total maxillectomy: 11 patients

- Orbital exenteration: 4 patients

- Antifungal treatment: Injection Amphotericin B

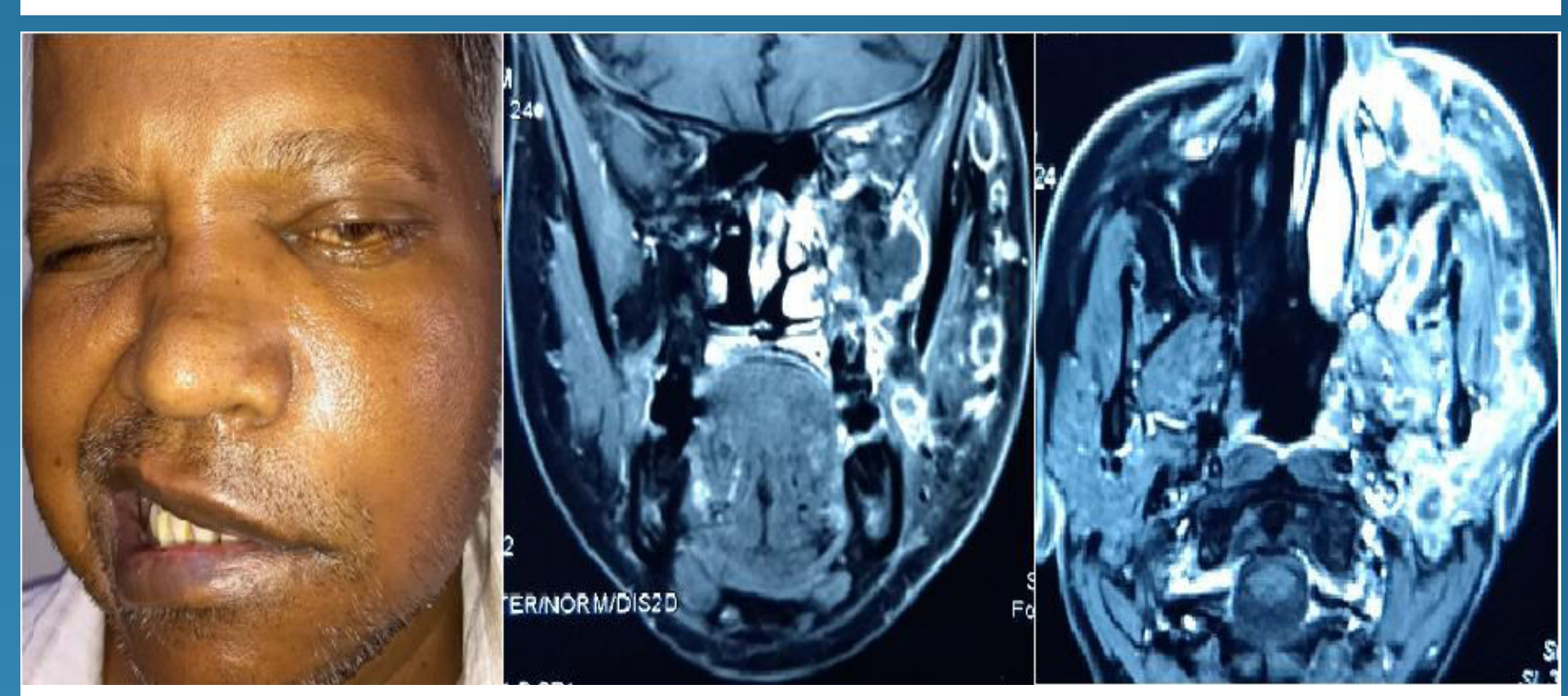

Figure 5. Mucormycosis involving the left infraatemporal fossa, parotid gland, and causing facial palsy in a 60-year-old diabetic

\section{OUTCOMES}

- Multiple debridement procedures were required in 10 patients

- Due to amphotericin B toxicity, its liposomal formulation was required in 28 patients

- Facial nerve paralysis persisted in all the 5 patients even after complete treatment

- Duration of hospitalization: 8-12 weeks

- Mortality rate: $29 \%$ (15 patients)

- Patients in diabetic ketoacidosis had a poorer outcome.

- All the 10 patients with intracranial extension developed cavernous sinus thrombosis with ophthalmoplegia and eventually died.

- Causes of death were intracranial extension (in 10 patients), sepsis (in 3 patients) and chronic renal failure (in 2 patients).

- On 1 year follow up, recurrence was seen in 4 patients.

\section{CONCLUSION}

- EARLY DIAGNOSIS \& TREATMENT

- High morbidity and mortality

- Intracranial spread has poor prognosis despite aggressive medical and surgical therapy.

- Literature: mostly case reports or small case series. This is one of the largest case series reported till date.

Copyright @ 2018 Dr Avani Jain

Department of Otorhinolaryngology, Maulana Azad Medical College and Lok Nayak Hospital, New Delhi, India

Email: avanijain87@hotmail.com 